\title{
Penyerapan Kosakata Bahasa Daerah ke dalam Bahasa Indonesia pada Kamus Besar Bahasa Indonesia Edisi Keempat
}

\author{
Adi Budiwiyanto*)
}

\begin{abstract}
Multicultural and multilingual situation in Indonesia lead to language contact that allows borrowing among the languages. The borrowing of local languages, especially the cultural vocabulary, needs to be encouraged in Indonesia language development since the local languages are 'seedlings' for the Indonesian vocabulary. Moreover, the rapid growth of science and technology needs to be balanced with the growth of words or terms. This paper discusses the contribution of the local languages in Indonesia to Indonesian vocabulary, especially in the Indonesian Comprehensive Dictionary, the Fourth Edition. Besides, the domain of the words borrowed and the changes occurred, either the form or the meaning, are discussed as well.
\end{abstract}

Key Words: multilingual, local language, borrowing, contribution

\footnotetext{
*) Sarjana Sastra, Pembantu Pimpinan pada Pusat Bahasa, Depdiknas
} 


\section{Pengantar}

Indonesia terdiri atas berbagai suku dengan masingmasing bahasanya. Berdasarkan laporan awal hasil Pemetaan Bahasa-Bahasa di Indonesia yang dilakukan oleh Pusat Bahasa, telah teridentifikasi sejumlah 442 bahasa. Jumlah tersebut masih bisa bertambah karena masih terdapat kurang lebih 300 daerah sampel penelitian yang tersebar di Papua, Maluku, Maluku Utara, dan Nusa Tenggara Timur yang sedang/akan diambil data kebahasaannya (lihat Mahsun, 2009:12). Di dalam situasi yang multikultural dan multilingual tersebut, sentuh bahasa dan sentuh budaya tidak dapat dihindari. Kontak bahasa ini menimbulkan saling serap antara unsur bahasa yang satu ke dalam bahasa yang lain.

Penyerapan kosakata bahasa daerah, terutama kosakata budaya, merupakan suatu usaha yang harus didukung dalam usaha pengembangan bahasa Indonesia. Dukungan tersebut layak diberikan karena ternyata banyak sekali konsep-konsep yang berasal dari kosakata bahasa daerah yang tidak dapat ditemui dalam konsep bahasa Indonesia dan kalaupun ada, bentuknya biasanya berupa frasa. Selain itu, kosakata bahasa daerah juga memiliki ungkapan yang berisi nilai-nilai kearifan lokal yang biasanya hanya dapat dijumpai dalam bahasa-bahasa tertentu.

Selain itu, seiring dengan perkembangan ilmu pengetahuan dan teknologi yang cepat, maka perkembangan itu juga harus diimbangi dengan pengembangan kosakata/istilah. Kosakata serapan dari bahasa daerah, dalam hal ini, dapat dimanfaatkan sebagai media alternatifnya. Sejauh ini, sudah ada beberapa istilah yang telah dimanfaatkan dan sudah diterima oleh masyarakat, misalnya kata unduh dan unggah yang diserap dari bahasa Jawa yang digunakan 
sebagai padanan dari kata kosakata bahasa daerah telah

download dan upload.

Usaha

penyerapan

kosakata tersebut tentunya harus diikuti dengan kodifikasi sehingga nantinya akan tercipta keteraturan bentuk yang sesuai dengan kaidah pemakaian bahasa Indonesia. Salah satu bentuk produk kodifikasi itu ialah Kamus Besar Bahasa Indonesia (KBBI). KBBI juga menjadi penting karena kamus ini dibuat oleh lembaga pemerintah dan dipakai sebagai acuan oleh masyarakat. Selain itu, keberagaman kosakata bahasa daerah yang terserap di dalamnya dapat menjadi salah satu tolok ukur seberapa jauh pemerintah memperhatikan bahasa-bahasa daerah di nusantara. Dalam konteks persatuan, dimasukannya kosakata bahasa daerah secara tidak langsung akan menumbuhkan rasa memiliki bahasa Indonesia.

Makalah ini akan menguraikan (1) sejauh mana diserap ke dalam ke dalam kosakata bahasa Indonesia, khususnya yang termuat di dalam KBBI Pusat Bahasa Edisi Keempat, (2) ranah kosakata yang diserap, (3) perubahan bentuk dan makna yang terjadi dalam proses penyerapan.

\section{Pembahasan}

\subsection{Kontribusi Kosakata Bahasa} Daerah dalam KBBI Pedoman

Umum

Pembentukan Istilah (PUPI) menyebutkan bahwa bahan baku istilah Indonesia diambil dari berbagai sumber, terutama dari tiga golongan bahasa yang penting, yakni (1) bahasa Indonesia, termasuk unsur serapannya, dan bahasa melayu, (2) bahasa Nusantara yang serumpun, termasuk bahasa Jawa Kuno, (3) bahasa asing, seperti bahasa Inggris dan bahasa Arab. Dari urutan tersebut, terlihat bahwa kosakata yang berasal dari bahasa daerah lebih dahulu 
4 Mabasan - Vol. 3 No. 1 Januari-Juni 2009: 1--14

daripada bahasa asing. Itu kata dan dengan melihat informasi menyiratkan bahwa penyerapan asal bahasa dalam definisi (lihat istilah ke dalam bahasa Indonesia Petunjuk Pemakaian KBBI). mengutamakan bahasa daerah Bahasa Melayu dengan berbagai terlebih dahulu.

dialeknya tidak dianggap sebagai

Di dalam KBBI Pusat bahasa daerah. Meskipun Bahasa Edisi Keempat, kosakata demikian, kontribusinya dalam daerah dapat dikenali dengan dua kosakata bahasa Indonesia akan cara, yaitu dengan melihat label disajikan dalam tulisan ini. yang ditulis antara lema dan kelas

Tabel 1: Bahasa Melayu dan Dialeknya

\begin{tabular}{|c|c|c|c|c|}
\hline No. & Dialek & Label & $\begin{array}{c}\text { Jumlah } \\
\text { Kosakata }\end{array}$ & Persentase \\
\hline 1 & Melayu Jakarta & $J k$ & 454 & 78,01 \\
\hline 2 & Melayu Jambi & $\mathrm{Jb}$ & 44 & 7,56 \\
\hline 3 & Melayu Medan & $M d$ & 26 & 4,47 \\
\hline 4 & Melayu Riau & $R i$ & 25 & 4,30 \\
\hline 5 & Melayu Malaysia & Mal & 14 & 2,41 \\
\hline 6 & $\begin{array}{c}\text { Melayu } \\
\text { Kalimantan }\end{array}$ & $K \operatorname{lm}$ & 11 & 1,89 \\
\hline \multirow[t]{2}{*}{7} & Melayu Manado & Mnd & 8 & 1,37 \\
\hline & \multicolumn{2}{|l|}{ Total } & 582 & \\
\hline
\end{tabular}

Berdasarkan

hitungan dengan hanya

memperhatikan

penggunaan bahasa daerah,

diketahui kosakata serapan bahasa daerah berjumlah 3.631 dari 72 bahasa. Berikut ini akan disajikan tabel lengkap bahasa daerah dan jumlah kosakata yang diserap. 
Tabel 2: Bahasa-bahasa Daerah dan Jumlah Kosakata Terserap

\begin{tabular}{|c|l|c|c|c|l|}
\hline No. & Bahasa & Label & $\begin{array}{c}\text { Jumlah } \\
\text { kosakata }\end{array}$ & Persentase & \multicolumn{1}{|c|}{ Provinsi } \\
\hline & Jawa & $J w$ & 1109 & 30,54 & Jawa Tengah, DI \\
\hline 2 & Minangkabau & $M k$ & 929 & 25,59 & Sumatera Barat \\
\hline 3 & Sunda & $S d$ & 223 & 6,14 & Jawa Barat \\
\hline 4 & Madura & $M d r$ & 221 & 6,09 & Jawa Timur \\
\hline 5 & Bali & $B l$ & 153 & 4,21 & Bali \\
\hline 6 & Aceh & $A c h$ & 112 & 3,08 & Aceh \\
\hline 7 & Banjar & $B j r$ & 100 & 2,75 & Kalimantai Timur \\
\hline & & & & & Sulawesi \\
8 & Muna & $M u$ & 63 & 1,74 & Tenggara \\
\hline 9 & Using & $U s$ & 46 & 1,27 & Jawa Timur \\
\hline 10 & Gayo & $G y$ & 45 & 1,24 & Aceh \\
\hline & & & & & Sulawesi \\
11 & Tolaki & $T l k$ & 42 & 1,16 & Tenggara \\
\hline & & & & & Sulawesi \\
12 & Wolio & $W l$ & 36 & 0,99 & Tenggara \\
\hline 13 & Muyu & $M y$ & 33 & 0,91 & Papua \\
\hline 14 & Batak & $B t$ & 32 & 0,88 & Sumatera Utara \\
\hline 15 & Alas & $A l s$ & 30 & 0,83 & Aceh \\
\hline 16 & Kaili & $K a l$ & 30 & 0,83 & Sulawesi Tengah \\
\hline 17 & Palembang & $P l b$ & 28 & 0,77 & Sumatera Selatan \\
\hline 18 & Bugis & $B g$ & 24 & 0,66 & Sulawesi Selatan \\
\hline & & & & & Kalimantan \\
19 & Dayak & $D y$ & 20 & 0,55 & Tengah \\
\hline 20 & Sangir/sangihe & $S n g$ & 19 & 0,52 & Sulawesi Utara \\
\hline 21 & Sasak & $S k$ & 18 & 0,50 & NTB \\
\hline 22 & Lampung & $L p$ & 17 & 0,47 & Lampung \\
\hline 23 & Benuaq & $B n$ & 16 & 0,44 & Kalimantan Timur \\
\hline 24 & Makassar & $M k s$ & 15 & 0,41 & Sulawesi Selatan \\
\hline 25 & Berik & $B r k$ & 14 & 0,39 & Papua \\
\hline 26 & Jayawijaya & $J y w$ & 13 & 0,36 & Papua \\
\hline 27 & Sumbawa & $S b$ & 13 & 0,36 & NTB \\
\hline 28 & Papua & $P p$ & 12 & 0,33 & Papua \\
\hline 29 & Putuk & $P t k$ & 12 & 0,33 & Kalimantan Timur \\
\hline 30 & Dani & $D n$ & 11 & 0,30 & Papua \\
\hline & Melayu & $K l m$ & 11 & 0,30 & Kalimantan \\
\hline 31 & Kalimantan & & & & Sulawesi \\
32 & Pulo/Wakatobi & $P l / W k t$ & 11 & 0,30 & Tenggara \\
\hline 33 & Minahasa & $M n$ & 10 & 0,28 & Papua \\
\hline & & & & \\
\hline
\end{tabular}


6 Mabasan - Vol. 3 No. 1 Januari-Juni 2009: 1--14

\begin{tabular}{|c|c|c|c|c|c|}
\hline 34 & Mandar & $M r$ & 10 & 0,28 & Sulawesi Selatan \\
\hline 35 & Tombulu & $T b l$ & 10 & 0,28 & Sulawesi Utara \\
\hline 36 & $\begin{array}{l}\text { Minahasa } \\
\text { Tonsea }\end{array}$ & Tns & 10 & 0,28 & Sulawesi Utara \\
\hline 37 & Abrab & $A b r$ & 9 & 0,25 & Papua \\
\hline 38 & Sentani & Stn & 8 & 0,22 & Papua \\
\hline 39 & Toulour & $T l$ & 8 & 0,22 & Sulawesi Utara \\
\hline 40 & Toraja & $T r j$ & 7 & 0,19 & Sulawesi Selatan \\
\hline 41 & Bugis-Makassar & $B g M$ & 6 & 0,17 & Sulawesi Selatan \\
\hline 42 & Bima & $B m$ & 6 & 0,17 & NTB \\
\hline 43 & Kapuas Hulu & $K h$ & 6 & 0,17 & Kalimantan Barat \\
\hline 44 & Kamoro & $K m r$ & 6 & 0,17 & Papua \\
\hline 45 & Talaud & Tld & 6 & 0,17 & Sulawesi Utara \\
\hline 46 & Waropen & $W r p$ & 6 & 0,17 & Papua \\
\hline 47 & Biak & $B k$ & 5 & 0,14 & Papua \\
\hline 48 & Ekagi & $E k g$ & 5 & 0,14 & Papua \\
\hline 49 & Fakfak & $F f$ & 5 & 0,14 & Papua \\
\hline 50 & Kulawi & Kul & 5 & 0,14 & Sulawesi Tengah \\
\hline 51 & Massenrempulu & $M p$ & 5 & 0,14 & Sulawesi Selatan \\
\hline 52 & Sorong & $\mathrm{Sr}$ & 5 & 0,14 & Papua \\
\hline 53 & Asmat & Asm & 4 & 0,11 & Papua \\
\hline 54 & Wamena & $W m n$ & 4 & 0,11 & Papua \\
\hline 55 & Aji & $A j$ & 3 & 0,08 & Sumatera Selatan \\
\hline 56 & Basemah & Bsm & 3 & 0,08 & Sumatera Selatan \\
\hline 57 & Mimika & $M m k$ & 3 & 0,08 & Papua \\
\hline 58 & Sekayu & Sky & 3 & 0,08 & Sumatera Selatan \\
\hline 59 & $\begin{array}{l}\text { Pegunungan } \\
\text { Tengah }\end{array}$ & $P n T$ & 2 & 0,06 & Papua \\
\hline 60 & Awyu & $A w y$ & 1 & 0,03 & Papua \\
\hline 61 & Baliem & Blm & 1 & 0,03 & Papua \\
\hline 62 & Bauzi & $B z$ & 1 & 0,03 & Papua \\
\hline 63 & Damal/amungkal & $D m / A m k$ & 1 & 0,03 & Papua \\
\hline 64 & Jayapura & Jyp & 1 & 0,03 & Papua \\
\hline 65 & Kimaam & $K m$ & 1 & 0,03 & Papua \\
\hline 66 & Kaureh & $K r$ & 1 & 0,03 & Papua \\
\hline 67 & Lengkayap & $L k p$ & 1 & 0,03 & Sumatera Selatan \\
\hline 68 & $\begin{array}{l}\text { Bian Marind } \\
\text { Deg }\end{array}$ & Mrd & 1 & 0,03 & Papua \\
\hline 69 & Ormu & $O r$ & 1 & 0,03 & Papua \\
\hline 70 & Petapa & $P t$ & 1 & 0,03 & Sulawesi Tengah \\
\hline 71 & Rampi & Ram & 1 & 0,03 & Sulawesi Tengah \\
\hline 72 & Wandamen & $W d m$ & 1 & 0,03 & Papua \\
\hline \multicolumn{3}{|c|}{ Total } & 3631 & & \\
\hline
\end{tabular}


Dari tabel di atas, bahasa Jawa menempati urutan teratas dalam kontribusinya terhadap pengembangan kosakata nasional sebesar $\quad 30,54 \%$. Berturut-turut disusul oleh bahasa Minangkabau, Sunda, Madura, Bali, Aceh, dan Banjar. Bahasa-bahasa itu secara geografis terletak di wilayah barat Indonesia. Kemudian, Di urutan bawah, umumnya di tempati oleh bahasa-bahasa di sebelah timur Indonesia, terutama Papua.

Berdasarkan jumlah penuturnya, terdapat 13 bahasa daerah yang penuturnya di atas satu juta orang, yaitu bahasa Jawa (75.200.000), Sunda (27.000.000), Melayu (20.000.000), Madura (13.694.000), Minang (6.500.000), Batak (5.150.000),

Bugis (4.000.000), Bali (3.800.000), Aceh (3.000.000),

Sasak (2.100.000), Makassar (1.600.000), Lampung (1.500.000), dan Rejang (1.000.000) (Bakorsutanal,
Besarnya jumlah penutur ternyata berkorelasi dengan jumlah kosakata bahasa daerah yang diserap ke dalam bahasa Indonesia. Makin besar jumlah penuturnya, makin besar kosakata yang diserap. Selain itu, proses penyerapan kosakata di dalam sejarah bahasa Melayu/Indonesia sudah lama berjalan. Jadi, tidaklah mengherankan jika bahasa serumpun yang jumlah penuturnya tergolong besar merupakan sumber yang kaya.

Selain jumlah penutur, ada beberapa faktor lain yang memengaruhi banyak sedikitnya kosakata bahasa daerah diserap ke dalam bahasa Indonesia, khususnya ke dalam $K B B I$, yaitu
a. kekerapan penggunaan kosakata bahasa daerah oleh wartawan pada media massa;
b. kekerapan penggunaan kosakata bahasa daerah oleh penulis atau sastrawan dalam karangannya;

diunduh 2 Juni 2009). 
8 Mabasan - Vol. 3 No. 1 Januari-Juni 2009: 1--14

c. kekerapan

penggunaan

kosakata bahasa daerah oleh tokoh publik;

d. ketersediaan konsep-konsep

baru pada kosakata bahasa daerah yang tidak dimiliki oleh bahasa Indonesia; dan

e. latar belakang penyusun $K B B I$.

\subsection{Klasifikasi Kosakata Bahasa Daerah}

Kosakata serapan dari

bahasa daerah pada KBBI Edisi

Keempat secara umum dapat

dikelompokkan sebagai berikut.

\section{a. Agama/Religi}

melasti $B l n$ upacara penyucian arca-arca simbol dewa dsb di laut

pancawalikrama $B l n$ upacara kurban yg diadakan 10 tahun sekali menjelang Hari

Raya Saka, Nyepi, tujuannya agar masyarakat dan negara bersih dan selamat, terhindar dr malapetaka, dsb

ajengan $S d n$ orang terkemuka, terutama guru agama Islam; kiai

dahopi $M u n$ persembahan doa dng sesajen (kpd leluhur yg dilakukan pd bulan puasa)

b. Bangunan

berugak $S k n$ bangunan berupa panggung terbuka dng empat atau enam tiang beratap berbentuk spt lumbung

caping $B l n$ hiasan pd sudut-sudut tiang bangunan

cungkup $J w n$ bangunan beratap di atas makam sbg pelindung makam; rumah kubur

rangkiang $M k n$ bangunan bertiang empat, biasanya berbentuk gonjong, berada di depan rumah gadang untuk tempat menyimpan padi c. Budaya

tajen /tajén/ $B l n$ sabung ayam

ngaben /ngabén/ $B l n$ upacara pembakaran jenazah pd masyarakat Bali yg beragama Hindu; carok $M d r n$ perkelahian dng menggunakan senjata tajam yg dilakukan secara ksatria satu lawan satu

suarang $M k n 1$ harta milik bersama, hasil pencaharian suami istri selama dl perkawinan; gana-gini

\section{d. Flora}

batun $B t n$ pohon, tinggi mencapai $30 \mathrm{~m}$, kayunya kuat dan awet, digunakan untuk bangunan rumah, jembatan, kerangka perahu, dsb; Pterospermum acerifolium

sibalaya Kal $n$ tanaman semak yg daunnya kecil dan berbau tajam, batangnya digunakan untuk menyapu halaman

saik Wmn $n$ buah merah

apa $M d r n$ buah tanaman sirih

\section{e. Fauna}

bagong $S d n$ babi hutan; celeng bangkung $B l n$ induk babi

kucit $B l n$ anak babi

beludak $J w n$ ular berbisa yg dapat menggembungkan lehernya (tengkuknya); ular sendok; ular tedung; Naja sputatrix

\section{f. Gelar}

anang Bjr $n 1$ gelar kebangsawanan Banjar aom $S d n$ gelar untuk anak bupati zaman dulu cokorda $B l n$ gelar bangsawan (golongan atau kasta kesatria)

dinaju Mdr $n$ gelar putri bangsawan Madura

g. Pangkat

bahu $J w n$ pangkat pembantu kepala desa rangga $J w n 1$ kata sapaan kpd pegawai kerajaan; 2 pangkat pegawai kerajaan sepandri $J w n$ pangkat serdadu (lebih tinggi sedikit dp serdadu biasa)

saka $M k n 1$ keluarga dr pihak ibu; 2 pangkat adat dr kaum yg bersifat turun-temurun

h. Jabatan

sangadi $n T l$ kepala desa yg bertugas mengatur pembagian aliran air sungai sarageni $S d n$ prajurit yg bertugas menembakkan meriam jagabaya $J w n$ kepala keamanan desa 
osara $T l k n$ kepala adat yg bertugas menyelesaikan perselisihan pewarisan, dan masalah-masalah adat

\section{i. Profesi}

anjun $S d n$ orang yg pekerjaannya

membuat barang gerabah

bong $J w n$ orang yg pekerjaannya

mengkhitan (menyunat); dukun sunat

nyarawedi $S d n$ orang yg pekerjaannya

menggosok permata

paledang /palédang/ $S d n$ orang yg

pekerjaannya membuat barang-barang $\mathrm{dr}$ tembaga

$\mathrm{j}$.

j. Kerabat

teteh /tétéh/ $S d n$ panggilan kpd kakak perempuan

mbok $B l n$ kata sapaan untuk perempuan yg lebih tua di Bali

mbak $n 1$ kata sapaan yg lebih tua di daerah Jawa; mbakyu; 2 kata sapaan untuk perempuan muda

uni $M k n$ kakak perempuan

\section{k. Kesehatan}

buduk $n 1 J w$ kusta; $2 S d$ beruntus dan gatal-gatal krn kuman pd kulit

corob $S d n$ penyakit kulit; bercak-bercak putih (pd tangan)

balayan $M k n$ penyakit kulit spt bisul, yg tumbuh pd bagian kepala dan

meninggalkan bekas

apid $\mathrm{Bl}$ a merah-merah pd lipatan kulit

(leher, paha)

\section{Olahraga dan Permainan}

ciblon $J w n$ permainan anak-anak ketika mandi di sungai atau di permandian dng cara menepak-nepakkan telapak tangan pd permukaan air sehingga menimbulkan bunyi tertentu

lengko-lengko $W l n$ permainan yg pemainnya senantiasa menggoyanggoyangkan sejumlah siput kecil disebuah tempurung kelapa

metai-tai /métai-tai/ Tlk $n$ permainan yg dilakukan dng cara meletakkan satu bungkusan kecil atau barang-barang lain di dekat pantat kawan sepermainannya tanpa diketahui pemain yg bersangkutan penteng /penténg/ Mdr $n$ permainan mengadu ketangkasan melontarkan sepotong kayu dr lubang dng dorongan batang kayu pemukul

m. Perabot

cudang $L p n$ tabung bambu tempat menyimpan air yg telah dimasak untuk dibawa ke ladang cempor $S d n$ lampu minyak yg tidak memakai semprong (biasanya dibuat dr kaleng bekas yg dilubangi untuk tempat sumbu)

jun $J w n$ buyung (tempat air) atau tempayan kecil dibuat dr tanah pekoro /pékoro/ Kmr $n$ piring kayu pd masyarakat suku Kamoro

\section{n. Perkakas}

berang $M d n$ pisau besar untuk merajang daun tembakau

bungkal $M d r n$ lempeng batu asahan halus untuk menajamkan pisau cukur cetok/cétok/ $J w n$ alat untuk mencedok adukan semen, tanah, dsb gantar $S d n$ galah

\section{o. Senjata}

berang $S b n$ senjata parang khas

Sumbawa

ces /cés/ Asm $n$ anak panah yg terbuat dr jali-jali

lancur $U s$ n senjata tajam (pedang) yg lengkung ke bagian yg tajam dao $n B z$ tombak yg digunakan untuk menangkap buaya

\section{p. Seni}

calung $S d n$ Mus alat musik pukul dr bambu bulat, ada yg menyerupai gambang, ada yg tersusun melintang dr atas ke bawah $\operatorname{dap} J b n$ alat musik khas Kerinci terbuat dr bongkol kelapa dan kulit kambing, dibunyikan dan dimainkan untuk menurunkan benda-benda pusaka kecimol $S k n$ dangdut jalanan, biasanya dipakai untuk mengiring pengantin di daerah Lombok gemblak $J w n 1$ penari (ronggeng) laki-laki 


\section{q. Tata Boga}

sanjai $M k n$ penganan dr singkong yg diiris tipis memanjang atau melebar, digoreng, dibumbui dng cabai merah

ambal $\operatorname{Tn} s$ penganan khas Tonsea terbuat $\mathrm{dr}$ adonan tepung ketan, lemak babi, dan jahe, dibungkus dng daun, lalu dimasak atau dikukus dl talang atau buluh

barongko $B g M n$ penganan kukus khas Bugis-Makassar, dibuat $\mathrm{dr}$ pisang yg sudah dihancurkan dicampur dng tepung, telur, dan gula pasir

berengkes /beréngkés/ $S k n$ makanan yg dibuat dr campuran kepala atau tulang ikan yg dibumbui kemiri, dibungkus dng daun pisang, kemudian dibakar

\section{r. Tata Busana}

tanggui Bjr $n$ topi perempuan khas Banjar berbentuk setengah bola besar terbuat dr daun pandan paksangko $P l b n$ pakaian adat pengantin Palembang berupa baju kurung panjang

boko $M r n$ nama pakaian adat perempuan Mandar yg sudah agak lanjut usia, biasanya berwarna putih, hitam, cokelat, atau biru, dipakai pd acara-acara penting surjan $J w n$ baju jas laki-laki khas Jawa berkerah tegak, berlengan panjang, terbuat dr bahan lurik atau cita berkembang

\section{s. Transportasi}

pincara $B g n$ alat penyeberangan dibuat dr dua buah perahu yg saling digandenngkan atau drum-drum kosong yg disusun, kemudian di atasnya diberi papan, digerakkan dng cara menarik tali yg telah disambungkan dng tali utama yg terbentang di atas kedua sisi sungai sawado Wrp $n$ perahu tidak bercadik

sope /sopé/ Mks n perahu bercadik ganda (kiri dan kanan) dilengkapi dng layar berbentuk segi empat untuk penggerak laju perahu gotrok $J w n$ kereta api kecil (untuk mengangkut tebu dsb); lori t. Ukuran

caing $S d n$ satuan ukuran yg jumlahnya sama dng 200 ikat (tt padi) cengkal $J w n$ satuan ukuran panjang sekitar 3,75 m atau 12 kaki; tombak

musti $B l n$ satuan ukuran sepanjang kepalan tangan ditambah panjang ibu jari, untuk menentukan jarak antarbangunan guli $B l n$ ruas jari tangan (biasanya yg terpanjang), digunakan sbg ukuran dl arsitektur tradisional

u. Waktu

Anggarakasih $J w n$ Selasa Kliwon cuduh $M k n$ rentang waktu yg tidak terlalu lama dr waktu terjadinya peristiwa (biasanya paling lama 2 jam)

titimangsa $J w n$ masa; waktu sangkala $J w n$ ketika; waktu

\section{v. Warna}

cemani $J w$ a hitam sama sekali (sampai ke tulang-tulangnya) deragem $J w$ a cokelat tua (tt warna kuda)

ganih $M k n$ putih (tt kain)

\section{w. Umum}

deng.kleng /déngkléng/, men.deng.kleng $B l v$ berdiri dng menggunakan satu kaki raweet /raweét/Ach $v$ menyisir rambut dng jari-jari tangan

sangkol $B l \quad v \quad$ menggendong (biasanya anak kecil) dng melingkar di pinggang kiri atau kanan

cengkung Gy $v$ duduk dng posisi kaki dilipat serta diangkat sambil bermenung

renyok, merenyok Ach $v$ mengangkat kemudian menjatuhkan keras-keras ke bawah dan menarik atau menggoyang-goyang (tt karung beras supaya padat isinya)

Dua puluh tiga ranah dalam pengklasifikasian di atas mencerminkan potensi kekayaan 
kosakata bahasa daerah. Masih yang baru, yang berasal dari banyak konsep yang tidak ada di Nusantara dilakukan dengan dalam bahasa Indonesia yang perekaciptaan, misalnya (pondasi) harus digali. cakar ayam, (penyangga)

\subsection{Perubahan Bentuk dan sosrobahu.} Makna Kosakata Serapan

Berdasarkan

Bagan

Prosedur Pembakuan Istilah (PUPI: 22), konsep dan istilah yang sudah ada, yang berasal dari Nusantara dilakukan dengan cara pemantapan, misalnya kata bhinneka tunggal ika, batik.

Sementara itu, konsep dan istilah

$$
\begin{aligned}
& \text { a. diftong ay } \rightarrow \text { ai } \quad \text { : bubuay }(S d) \rightarrow \text { bubuai } \\
& \text { ow } \rightarrow \text { ou } \quad: \text { maharow (Lp) } \rightarrow \text { maharou } \\
& \text { b. konsonan th } \rightarrow \text { th } \quad \text { : canthuk }(U s) \quad \rightarrow \text { cantuk } \\
& \text { bh } \rightarrow \text { b : pogau kabhala }(\mathrm{Mu}) \rightarrow \text { pogau kabala } \\
& g \rightarrow \mathrm{k} \quad \text { :awig-awig }(B l) \quad \rightarrow \text { awik-awik } \\
& \text { pp } \rightarrow p \quad \text { : inappu }(D n) \quad \rightarrow \text { inapu } \\
& o \rightarrow a \quad \text { :iro }(M k) \quad \rightarrow \text { ira } \\
& \text { puro }(M k) \rightarrow \text { pura } \\
& \text { buto }(\mathrm{Jw}) \rightarrow \text { buta } \\
& \text { eu } \rightarrow e \quad: \text { akeul }(S d) \quad \rightarrow \text { akel } \\
& \text { ayeuh }(S d) \rightarrow \text { ayeh }
\end{aligned}
$$

Perubahan makna yang dalam bahasa Minangkabau berarti terdapat di dalam KBBI umumnya redup, kini berkembang menjadi adalah peluasan makna. Sebagai lima makna. contoh, kata lindap yang awalnya 
lin.dap $M k$ a 1 redup; samar; (mulai) kabur; berkurang (tt cahaya, panas, terang): $k r n$ kehabisan minyak, sinar lampu itu mulai --; 2 (mulai) padam: api sudah --; 3 mendung: langit makin --; 4 kurang dapat ditangkap maknanya; kurang jelas: teriakannya -- ditelan lembah itu; $\mathbf{5}$ sejuk; teduh: marilah kita mencari tempat yg -- di antara pohon-pohon itu;

Begitu juga dengan kata cokok, mencokok, kata ini biasanya digunakan untuk menangkap ayam, ikan, dsb. Akan tetapi, sekarang penggunaannya diperluas untuk menangkap basah atau memergoki seseorang yang sedang melakukan sesuatu yang tidak baik.

Contoh lainnya adalah kata mangap yang dalam bahasa Jawa bermakna terbukal menganga, setelah diserap mendapat makna tambahan kiasan berbicara.

ma.ngap $J w \quad v \quad \mathbf{1}$ membuka mulut; menganga ( $\mathrm{tt}$ mulut); $2 \mathrm{ki}$ berbicara: jangan asal -- saja!

Masih banyak contoh lainnya lagi yang berkenaan dengan peluasan makna kosakata serapan bahasa di dalam KBBI.

\section{Penutup}

Kosakata bahasa daerah merupakan sumber dan benih pengembangan kosakata bahasa Indonesia. Penyerapan kosakata bahasa daerah bermanfaat untuk pemekaran dan pemerkaya bahasa Indonesia, serta untuk pengembangan bahasa daerah itu sendiri.

Besar kecilnya kosakata suatu bahasa daerah yang diserap ke dalam bahasa Indonesia, khususnya yang telah dimuat di dalam $K B B I$, janganlah dianggap sebagai satu-satunya ukuran dalam upaya pengembangan kosakata. Usaha untuk mengembangkan kosakata budaya tersebut harus terus dilakukan. Masyarakat harus didorong dan diberi kemudahan sehingga memiliki ruang gerak dan potensi untuk memperkenalkan atau 
memopulerkan budayanya melalui kosakata bahasa daerah.

Pemerintah, melalui lembaga/ instansi yang berwenang, juga harus mendukung upaya tersebut.

Hal lain yang perlu dilakukan adalah menanamkan rasa kesetiaan bahasa, kebanggaan bahasa, dan kesadaran bahasa. Kesetiaan bahasa akan mendukung terciptanya persatuan semua warga penutur bahasa Indonesia karena mereka merasa memiliki bahasa Indonesia. Kebanggaan bahasa akan mendorong pemahiran pengunaan bahasa Indonesia oleh masyarakatnya. Kesadaran bahasa akan membawa kita untuk menjadi teladan dalam pemakaian bahasa Indonesia yang baik.

\section{Daftar Pustaka}

Bakorsutanal. (2007). "Prinsip, Kebijakan dan Prosedur Pembakuan Nama Rupabumi".

(http://www.bakosurtanal.go .id/upl document/perpres/ Bab 2 II.pdf, diunduh pada 2 Juni 2009).

Dendy Sugono. (2009). "Bahasa Daerah, Bahasa Indonesia, dan Bahasa Asing dalam Percepatan Realisasi Pendidikan Berkelanjutan bagi Anak Indonesia." Dalam Seminar Internasional Bahasa dan Pendidikan Anak Bangsa. Jakarta: Pusat Bahasa.

Departemen Pendidikan Nasional. (2008). Kamus Besar Bahasa Indonesia Pusat Bahasa: Edisi Keempat. Jakarta: Gramedia Pustaka Utama.

Kisyani-Laksono.

"Pelestarian

(2009).

Pengembangan Bahasa-

Bahasa Daerah di

Indonesia." Dalam Seminar Internasional Bahasa dan Pendidikan Anak Bangsa. Jakarta: Pusat Bahasa.

Mahsun. (2009). "Beberapa Persoalan dalam Upaya Menjadikan Bahasa Ibu 
14 Mabasan - Vol. 3 No. 1 Januari-Juni 2009: 1--14

sebagai Bahasa Pengantar Pendidikan di Indonesia." Dalam Seminar Internasional Bahasa dan Pendidikan Anak Bangsa. Jakarta: Pusat Bahasa. diselenggarakan oleh Wacana, Jurnal Ilmu Pengetahuan Budaya berkoordinasi dengan Departemen Linguistik FIB Universitas Indonesia.

Moeliono, Anton M. (1989). Panitia Pengembangan Bahasa

Kembara

Kumpulan

Bahasa:

Karangan

Tersebar. Jakarta: 1989.

Moeliono, Anton M. (2009).

"Multilingualisme,

poliglosia, dan penyerapan unsur bahasa." Dalam Ceramah Linguistik
Indonesia. (2008). Pedoman Umum Pembentukan Istilah Edisi Ketiga. Jakarta: Pusat Bahasa.

Prawiroatmodjo, S. (1988). Bausastra Jawa-Indonesia. Jakarta: Haji Masagung. 